\title{
Building Research Competence of Graduate Students by Means of Teaching English for Academic Purposes
}

\author{
Gorelova Y.N. a \\ Zalyaeva E.0. $b$ \\ Sungatullina D.D. c
}

a bc Kazan Federal University, Institute of Management, Economics and Finance, Kazan, 420008, Russia

Email: gorelovajuliya@gmail.com

\section{Doi:10.5901/mjss.2015.v6n1s3p352}

\begin{abstract}
The purpose of the article is to study the potential of the "English for academic purposes" course for building research competence of graduate students. The article examines approaches to designing the syllabus for the course and determines its role in the development of learners research and academic skills. The article describes and analyses the course syllabus, highlights methods, materials and techniques used in the educational process, as well as typical practical assignments.
\end{abstract}

Keywords: graduate program, foreign language, academic reading, academic writing, syllabus, research paper.

\section{Introduction}

Changes in modern educational system and an integral participation of the Russian Federation in international academic environment require significant improvement of the current higher educational curriculum in order to meet the increasingly stringent requirements [Gorelova, 2014]. In addition, the ambitious targets set by the Russian government for a number of leading Russian higher educational establishments to be included in the list of world's leading universities also imply a radical change in priorities of higher education and focus on research. Thus, the capacity to conduct scientific research competently and reasonably as well as the ability to report on its results become important and relevant not only for researchers and faculty members, but also for undergraduates and graduate students[Baklashova, 2014].

However, in Russian universities, and this problem is typical for most of them, there are no distinct guidelines for building curriculum. The aim to build students' academic skills is generally not achieved as there are no specific courses in the curriculum, which implies the familiarity of leaners with the specifics of scientific discourse [Ismagilova, Polyakova, 2014]. At the same time, the existing realities require students and would-be professionals to have a deep knowledge of the latter not only in Russian Language, but in English as well [Khusainova, Rahmatullina, 2014], since the visibility of scientists in the world academic environment is only possible if the publications in the leading peer-reviewed journals are in English [Kalganova, 2014]. This begs the question of revising the curriculum for graduate programs in general as well as the syllabus for the "English Language for Specific Purposes" (ESP) in particular [Grigorieva, 2014], as the Russian higher education system is undergoing significant changes designed to affect the quality of training and graduate competitiveness in the world job market.

Based on the above mentioned conditions, requirements and contradictions, it seems appropriate to adjust the syllabus of the course "English Language for Specific Purposes" and make it more academically oriented, focusing specifically on reading and writing for research.

\section{Materials and Methods}

The main methods used are the methods of descriptive analysis of the existing second language learning theories as well as the method of authors' teaching experience post evaluation. 


\section{Theoretical Background (Syllabus Design)}

The status of the English language as an International language for academic communication increases the demand for ESP courses and changes the criteria to the course content, which needs to take into account the requirements of the changing educational environment and address professional and academic needs of learners [Chostelidoua, 2010].

Generally, English for Academic Purposes (EAP) professionals are often engaged in materials development activities because commercial textbooks and other instructional materials fall short of addressing their students' specific language learning needs [Stollera et al., 2006].

The authors share the opinion that approaches to designing syllabuses for EAP courses vary, and there is a tendency that "syllabus had to remain flexible. It could be supplemented by a variety of existing authentic material" [Edwards, 2000] and adjusted to the set requirements.

The methods for classifying syllabuses differ, thus one of the most functional concepts is the approach presented by Massoud Rahimpour [Rahimpour, 2010], where the following types of syllabuses are distinguished:

a) A structural syllabus is a kind of syllabus in which the content of language teaching is a collection of the forms and structures, usually grammatical elements such as verbs, nouns, past tense and so on.

b) A notional/functional syllabus is the one in which the content of the language is a collection of the functions that are to be performed when language is used, or of the notions that language is used to express. For example, informing, agreeing, apologizing, requesting, promising and so on.

c) A situational syllabus is one in which the content of language teaching is a collection of real or imaginary situations in which language occurs or is used For example. Seeing the dentist, asking directions in a new town, buying a book in a bookshop.

d) A skill-based syllabus is one in which the content of the language teaching is a collection of specific abilities that may play a part in using language.

e) A content-based syllabus is not really a language teaching syllabus at all. In content-based language teaching, the primary purpose of the instruction is to teach some content or information using the language that the students are also learning. The students are simultaneously language students and students of whatever content is being taught. The subject matter is primary, and language learning occurs incidentally to the content learning. An example of content-based language teaching is a science class taught in the language the students need or want to learn.

f) A task-based syllabus is one in which the content of the teaching is a series of complex and purposeful tasks that the students want or need to perform with the language they are learning.

The authors of the article having evaluated their past teaching experience as well as the needs of the potential learners both academic and professional have chosen a task-based approach to syllabus design as the course developed has a clear and specific objective - to teach graduate students to use the English language for performing their academic work.

\section{Results}

The implementation of a task-based approach within the framework of "English for academic purposes" determines sequencing and content selection of a program dedicated to graduate students teaching. To illustrate the basic components of a course we should also mention that EAP is designed to enable students to use English effectively in the academic contexts they will encounter in their studies[Galishnikova, 2014]. Thus, the program should focus on the following: formation of reading and writing skills though the introduction of the basics in types of reading (skimming, scanning, critical reading) and research paper sections (abstract, introduction, paragraph design and conclusion).

\section{Discussion}

The formation of reading and writing skills for research is a closely interrelated process: it is impossible to master academic writing without the ability to read, analyze scientific literature according to the major and extract the information needed [Mardanshina, Zhuravleva, 2014].

While doing a Master's degree a student collects material and makes a draft of his future research paper Master's thesis, and also reports on its main provisions in the publications. Consequently, all the disciplines studied should contribute to this process directly and indirectly, including "Foreign Language" course [Zalyaeva, Solodkova, 2014]. Therefore, a teacher faces much more complex tasks: 
- to teach academic reading;

- to teach academic writing;

- to motivate students to use the skills acquired when writing the master's thesis, as well as in their future research.

Student's introduction into the course usually begins with the analysis of the research paper (written in English) structural elements, revealing the typical features of each component, as well as considering the requirements for each section. A research paper in English usually comprises the following sections:

- title;

- abstract;

- keywords;

- introduction;

- materials and methods;

- results;

- discussion;

- conclusion;

- acknowledgements;

- references.

The materials for this type of work are the research papers of eminent scientists, who can be found in international citation databases, such as the Scopus and the Web of Science. The choice in favor of these databases is not random, because it is the Scopus and the Web of Science where leading academic publications are indexed, and their study may give an idea about the current state of a particular scientific field. In addition, within this section of the course an individual approach to studying is implemented [Kudryavtseva, 2014], as each student analyzes the article in his/her scientific field, collecting information for future research from competent sources.

While studying the structure of a research paper it is necessary to analyze its typical language elements inherent in scientific texts. They may include:

1. high lexical density and terminology;

2. quantitative predominance of nouns over verbs;

3. non-personal constructions [Coffee, Curry \& Goodman, 2005:28].

Having identified the peculiarities of the language structural elements, students proceed to the analysis of the research paper actual substantial component. The process begins with the development of two basic skills - skimming and scanning, as well as with critical reading. Skimming involves reading key parts of the text to get an overview of an author's main line of argument. There are two basic skim-reading techniques. Start-finish technique implies that the central ideas of the article are noted briefly in the introduction, discussed in detail in the body of the text and reviewed briefly in the conclusion. [Harwood, 2005: 52]. The first sentences strategy assumes that the first or opening sentence of each paragraph introduces the main point(s) to be discussed in that paragraph. Reading only the opening sentences of the paragraph often gives you a clear understanding of the author's reasoning and the structure of the argument than just relying on the introduction and conclusion [Spector-Cohen, 2001: 374].

Considerable importance is also attached to the ability to read and assess the abstract to the article, since it is a reference material and it introduces the content of the article, without requiring any access to the entire text. The significance of this ability is manifested in the process of finding literature on the subject of research.

Scanning is based on finding specific information and requires the ability to analyze the titles, subtitles, or content of the books and journal volumes [lkeda, 2006: 391].

While reading critically, students learn to take notes which is the first step to writing a research paper. Ability to take notes involves the ability to highlight the main ideas in the text and summarize them in the form which is different from the author's one. [Anderson, 2009] In other words, paraphrasing is one of the key writing skills, otherwise, there is a risk of being accused of plagiarism. Students learn such techniques of paraphrasing as replacement by synonymous lexical units, changing the sentence structure, replacement of parts of speech and etc. [Bailey, 2011: 52]. They also learn to use competently references and quotations within a text.

Having combined and changed the key points of the initial paper if necessary, students get their first piece of academic writing - a summary. The experience gained and the skills developed may assist students in making a review of relevant research papers, quoting their authors and referring to them. All these constitute the initial research skills.

Particular attention is paid to the abstract of the research paper. The abstract section in a scientific paper is a concise digest of the content of the paper. An abstract is more than a summary. A summary is a brief restatement of 
preceding text that is intended to orient a reader who has studied the preceding text. An abstract is intended to be selfexplanatory without reference to the paper, but is not a substitute for the paper [Yakhontova, 2001: 408].

Our observations show that abstract has definite structure and content including the aims of scientific research, materials and methods implied by the author, findings and conclusion.

An important implication of our findings is that all the previous activities, performed by a student preparing for his/her Master's degree, serve as a basis for the development of critical thinking skills: process of actively conceptualizing, applying, analyzing, synthesizing, and/or evaluating information gathered from different sources within one subject scope. The following exercises can be implemented in the course of instruction: compare the concepts brought forward by two different authors on the topic of ...; use the examples presented in the first article to illustrate the basic conceptual issues stated in the second one; combine the causes discussed in one article with the effects studied in the other and vice versa.

The next stage of our research is devoted to the study of a research paper writing process. At this point four patterns of a paragraph typical structure are introduced to the students [Bailey, 2011:100-101]:

There's no doubt that well-structured paragraphs help the reader to understand the topic more easily by dividing up the argument into convenient sections. The purpose of this detailed paragraph organization patterns analysis lies in the fact that students are supposed to master the technique of paragraph development. Initially the students are taught how to arrange a paragraph out of disjointed sentences. The second subsequent and more complicated task deals with the development of an idea within the framework of a topic given. For example, the students may be proposed to develop the idea stated in the sentence below: "It has been argued that rises in the rate of home ownership can increase the rate of unemployment" in accordance with a paragraph structure.

\section{Conclusion}

Summing up the results, it can be concluded that the potential of "The Foreign Language: Advanced Level" syllabus for students doing their Master's degree is broad and universal. Having regard to the globalization and internationalization processes which are currently affecting the system of higher education, the solution of problems such as building the capacity to conduct scientific research competently and reasonably as well as the ability to report on its results in English, will make a significant contribution to the development of Master Degree Students professional and research competencies and will facilitate their success in today's global educational and scientific domain.

\section{References}

Alavi, S. M., and Akbarian, I. (2012). The role of vocabulary size in predicting performance on TOEFL reading item types, in System, 40, (3): pp. 376-385.

Ames, W.S. (1966) The development of a classification scheme of contextual aids. Reading Research Quarterly 2, (1): pp. 57-82.

Anderson I. (2009). Avoiding plagiarism in academic writing. Nursing Standard, 23 (18): pp. 35-37.

Armbruster, B. B., Anderson, T. H., \& Ostertag, J. (1989). Teaching text structure to improve reading and writing. Reading Research Quarterly, 22, 331-346.

Bailey S. (2011). Academic writing. A handbook for international students: 3rd edition. Routledge.

Baklashova Tatiana (2014). Manager's Professional Training in Russia: Syllabus and Technologies. Procedia - Social and Behavioral Sciences, 152: pp. 1057-1061

Brown, H. Douglas (2004). Language Assessment: Principles and Classroom Instructions, New York: Longman.

Burke, J. (2000). Reading Reminders: Tools, Tips, and Techniques. Portsmouth, NH: Boynton/Cook.

Burns, P. and Roe, B. (1984). Teaching Reading in Today's Elementary Schools. Boston: Houghton Mifflin Company.

Coffee C., Curry M.Z., Goodman Sh. et al. (2005). Teaching academic writing: a toolkit for higher education. Routledge.

Dora Chostelidoua (2010). A needs analysis approach to ESP syllabus design in Greek tertiary education: a descriptive account of students' needs. Procedia Social and Behavioral Sciences 2: pp. 4507-4512.

Fredricka L. Stollera, Bradley Horna, William Grabea, Marin S. Robinson (2006). Evaluative review in materials development. Journal of English for Academic Purposes, 5: pp. 174-192.

Galishnikova Elena M. (2014). Language Learning Motivation: A Look at the Additional Program. Procedia - Social and Behavioral Sciences, 152: pp. 1137-1142

Gorelova Juliya N., (2014). Advertising Language as a Means of Forming Students' Cross-cultural Competence. Procedia - Social and Behavioral Sciences, 152: pp. 668-672.

Grigorieva Elena (2014). Language Teaching Content Renovation in the Context of Higher Education Internationalization. Procedia Social and Behavioral Sciences, 152: pp. 1143-1147

Harwood Nigel (2005). What do we want EAP teaching materials for? Journal of English for Academic Purposes, 4: pp.149-161. 
Ismagilova Liliya R., Polyakova Oksana V. (2014). The Problem of the Syllabus Design within the Competence Approach based on the Course "English for Master Degree Students in Economics (Advanced Level)". Procedia - Social and Behavioral Sciences, 152: pp. 1095-1100

Nathan Edwards (2000). Language for business: effective needs assessment, syllabus design and materials preparation in a practical ESP case study. English for Specific Purposes, 19: pp. 291-296.

Rahimpour Massoud (2010). Current trends on syllabus design in foreign language instruction. Procedia Social and Behavioral Sciences, 2: pp. 1660-1664.

Spector-Cohen E., Kirschner M., Wexler C. (2001). Designing EAP reading courses at the university level. English for Specific Purposes, 20: pp. 367-386.

Yakhontova T. (2001). Textbooks, contexts, and learners. English for Specific Purposes, 20: pp. 397-415. 